\title{
Practice of Laparoscopy Principles from Pages of Ancient History and Mythology
}

\author{
Aswini Misro \\ Received: 11 June 2014 / Accepted: 2 February 2015 /Published online: 21 February 2015 \\ (C) Association of Surgeons of India 2015
}

\begin{abstract}
The principles of laparoscopic and robotic surgery are fascinating. These have brought unprecedented transformation in the field of surgery. It is quite interesting to note the practice of the same core principles in the pages of history and mythology.
\end{abstract}

Keywords Laparoscopy $\cdot$ History $\cdot$ Mythology $\cdot$ Surgery

The principles of laparoscopic and robotic surgery are fascinating. These have brought unprecedented transformation in the field of surgery. It is quite interesting to note the practice of the same core principles in the pages of history and mythology. Laparoscopic procedures are virtual in nature. The laparoscopic surgeon is guided by the camera image rather than actual visual perception. It is intriguing that some of the gallantry warrior of the past fought and won utilising the same principle.

This example is from the Indian epic, Mahabharata. Incontrovertibly, Arjun was a most brilliant and stalwart archer of the Mahabharata times. A number of princes were vying for the hand of a beautiful princess called Draupadi in the arena of King Drupad. In order to win the hand of the princess, Arjun had to shoot an arrow into a golden fish attached to a revolving wheel on the ceiling by viewing at its reflection in a pan of water below. Arjun, undeterred and unmoved by all the other warrior's futile attempts, accomplished the task by looking at its reflection in the water below with unmistakable precision, amidst the tumultuous plaudits of the multitude gathered in the court.
Similar description is also found in the Greek Mythology during the beheading of a repugnant demon Medusa by the Greek demigod Perseus on the order of King Polydectes of Seriphus. Medusa was a grotesque-looking Gorgon who is said to have venomous snakes in place of locks of hair. This demon was almost invincible as the unfortunate ones who would gaze into her petrifying eyes would transform into stone and lose their existence. An ingenious Perseus was able to achieve this seemingly impossible task by meticulously pursuing the demon's reflection on his shield gifted by the goddess Athena while avoiding direct visual confrontation. Finally, with a mighty blow, he dismembered her head from her body by the "adamantine" sword .

Just like an archer envisaging the trajectory of an arrow and the power of a bow-cord based on real-time mirror image information about the distance and movement of a target object, a laparoscopy surgeon operates on the organs based on the virtual real-time image displayed on the laparoscopic monitor. This is titled as the hand-eye coordination which is the essential competency skill for performing these surgeries. The arena of abdominal compartment is dynamic with peristaltic bowels, pulsatile blood vessels, elusive bleeders and moving organs (due to breathing and heart movements), challenging the surgeons to choose the right weapon from their armamentarium and operate in the right direction, depth and momentum.

Clarence Darrow said "History repeats itself, and that's one of the things that's wrong with history". Whether we call it history or mythology, it is intriguing to note these repeats.

Conflict of Interest None.
A. Misro $(\bowtie)$

Department of Surgery, Lumbini Medical College, Palpa, Nepal

e-mail: draswini@gmail.com 